\section{Decompression and gutter splint techniques to prevent recurrence in ingrowing toenails}

\section{Eva Krishna Sutedja, Vina Feriza, Rachel Marsella Rahardjo, Dina Fatmasari, Reti Hindritiani, Hendra Gunawan, Oki Suwarsa}

Department of Dermatology and Venereology, Faculty of Medicine, Universitas Padjadjaran - Dr. Hasan Sadikin Hospital, Bandung 40161, West Java, Indonesia

\begin{abstract}
Ingrowing toenails (IT) is puncture of periungual skin by its surrounding nail plate. IT most frequently occurs in males aged 10-30 years. Pathogenesis of IT is multifactorial. Patients most commonly present with toe pain and may also complain erythema, swelling, or discharge from the nail edge. The clinical presentation of IT has been divided into three stages; stage I or inflammatory stages, stage II or abcess formation, and stage III or granulation tissue formation. IT is a nail disease with high reccurences that commonly seen in daily practice. Several treatment approaches ranging from conservative therapy (gutter splint) to surgical treatment (decompression technique). We report a case of IT in a 13-yearold boy that treated with decompression and gutter splint technique. The combination of this technique provides good results for IT and there was no recurrences after two months of observation.
\end{abstract}

\section{Introduction}

Ingrowing toenail (IT) also known as onychocryptosis or unguis incarnatus ${ }^{1,2}$ is a puncture of periungual skin by its surrounding nail plate, resulting in a cascade of foreign body, inflammatory, infections, and reparative processes. ${ }^{3}$ Incidence of IT peaks in second and third decade of life, with a male predominance of 2:1 over females. ${ }^{4}$ The main factors implicated in the development of an IT are poorly fitting shoes, improperly trimmed toenails, excessive sweating, nail infections, and nail apparatus abnormalities. There are various methods to treat IT includes gutter splint technique as a conservative therapy and decompression technique as a surgical treatment. The selec- tion of technique depends on the stage and severity of the disease, expertise of the surgeon, and the previous treatment of the patient. ${ }^{1}$ This report will discuss a case of IT which successfully treated with a combination of decompression and gutter splint technique.

\section{Case Reports}

A 13-year-old Indonesian boy presented with painful swelling and suppuration on his left thumb (Figure 1A). The patient complained that the symptoms started three weeks ago. He has been treated with topical and systemic antibiotics without improvement. There no history of similar complaint and the history of repetitive trauma, improperly trimmed toenails, and poorly fitting shoes were denied. On physical examination, we found stage II IT on the lateral side and stage I IT on the medial side of toenail. We treated the patients with topical and systemic antibiotics, and analgesic for 5 days, then we planned to perform a combination of decompression and gutter splint techniques.

The procedure of this combination technique as follows: Firstly, we cleaned the area with povidone iodine, then we did the surgical procedure with metatarsal block anesthesia and finger tourniquet. Subsequently, approximately $20-25 \%$ of the lateral nail plate was surgically avulsed (Figure 2A-B). A $1 \mathrm{~cm}$ diameter of the soft tissue on the side of the toe with onychocryptosis was cut elliptically along free margins of the nail without touching the nail bed and excised (Figure 2C-D). We slitted a small cut sterilized vinyl intravenous drip infusion tube with one end cut diagonally for medial nail plate (Figure 2E-G). The plastic tube then attached with adhesive tape (Figure 2H). Post operative care included advising the patient to avoid wearing shoes for 3 days, to keep the leg elevated for 24-48 hours. The dressing then removed on the day after surgery and was followed by cleaning with povidone iodine, twice daily for a week. Following the cleaning, the patient was advised to apply antibiotic ointment and small bandage. We prescribed mefenamic acid for 3 days and amoxicillin clavulanic acid for 5 days. Sutures were removed on the $13^{\text {th }}$ day postoperative and gutter splint was removed on the second month. Significant improvements were observed within two months after treatment (Figure 1B).

\section{Discussion}

The mechanism of IT occurs when the
Correspondence: Rachel Marsella Rahardjo, Department of Dermatology and Venereology, Faculty of Medicine, Universitas Padjadjaran - Dr. Hasan Sadikin Hospital, Bandung 40161 Indonesia.

Tel: +62222032426 ext. 3449 .

E-mail: rachel.marsella87@gmail.com

Key words: Decompression; gutter splint; ingrowing toenails.

Acknowledgments: The authors would like to extend our gratitude to the staff of the Department of Dermatology and Venereology, Faculty of Medicine, Universitas Padjadjaran who contributed to this work.

Received for publication: 1 February 2019. Accepted for publication: 22 February 2019.

This work is licensed under a Creative Commons Attribution-NonCommercial 4.0 International License (CC BY-NC 4.0).

(C) Copyright E.K. Sutedjaet al., 2019

Licensee PAGEPress, Italy

Dermatology Reports 2019; 11(s1):8084

doi:10.4081/dr.2019.8084

lateral nail fold is penetrated by the edge of the nail plate, resulting in pain and formation of granulation tissues. Penetration often caused by spicules of nail at the edge of the nail plate, which incite an inflammatory response. The great toe are the most affected. ${ }^{1,4}$ The predisposing factors in the development of an IT are ill-fitting shoes, tight socks, soft tissue abnormalities of the toe, pressure from walking, repititive trauma, hyperhydrosis, and improper nail trimming. ${ }^{1,2,4}$ Extrinsic compression of the great toe from poorly fitting shoes places constant pressure directly on the medial nail wall and indirectly on the lateral wall as the great toe is pushed against the second toe. The toenails should be cut straight across, instead of rounded. Cutting the nail short will allow more bulging of soft tissue, leading to an inflammatory reaction and pressure necrosis. Hyperhydrosis and maceration cause the skin of the nail folds to become soft that can be easily penetrated by the nail. Tinea unguium or onychomycotic nails cause the nail plate become brittle resulting in easy breaking off the nail spicules, making it easier for the nail to pierce surrounding skin. Improper shape of the nail plate, thick nail folds, medial rotation of the hallux (eversion), and reduced nail thickness can play a role in the pathogenesis of IT. ${ }^{1-3}$ Several comorbidities have been associated with IT, particularly in older patients, including diabetes, obesity, thyroid, cardiac, and renal disease. These 
diseases are thought to predispose patients to lower extremity swelling, leading to increased rates of ITs. ${ }^{4}$ In this case, the prediposing factors were ill-fitting shoes, improperly trimmed toenails, and repetitive trauma.

Patients almost universally present with toe pain. The pain may cause difficulty with walking, and in extreme cases, inability to ambulate. Patients may also complain of erythema, swelling, or discharge from the nail edge. ${ }^{4,5}$ Heifetz described the course of the disease by dividing it into 3 stages. The first stage referred as "inflammatory redness and swelling." This stage responds to non-operative treatment and often resolves on its own. Stage II is referred to as the stage of "inflammatory secretion" and can progress to stage III, which is marked by "granulation tissue formation."6 A recent classification by Mozena has described four stages of IT. The clinical features of stages I is erythema, mild edema, and pain on pressure applied to the lateral nail fold. The nail fold does not extend over the nail plate. In stage IIa, there are pain, edema, erythema, hyperesthesia, oozing, and infection. Nail fold extends over the nail plate and measures less than $3 \mathrm{~mm}$. Similar to stage IIa, the stage IIb is characterized by hyperthropic nail fold extends over the nail plate and measure more than $3 \mathrm{~mm}$. There are granulation tissue and chronic hyperthrophy of the nail fold, which widely covers the lateral nail plate on the stage III. In stage IV, the hyperthrophic tissue completely covers lateral, medial, and distal nail plate. ${ }^{1,7}$ In this case according to Heifetz classification, there was suppuration on the lateral side of toenail, then the patient was diagnosed as stage II IT, while the medial side of toenail diagnosed as stage I IT because there were erythema and pain on pressure.

Treatment of IT should be based on the patient's stage of involvement. ${ }^{3,8}$ Mild to moderate lesions with minimal to moderate pain, little erythema, and no purulent drainage can be treated with conservative therapy. Moderate to severe lesions with severe, disabling pain, erythema, and purulent drainage usually require surgical inter-
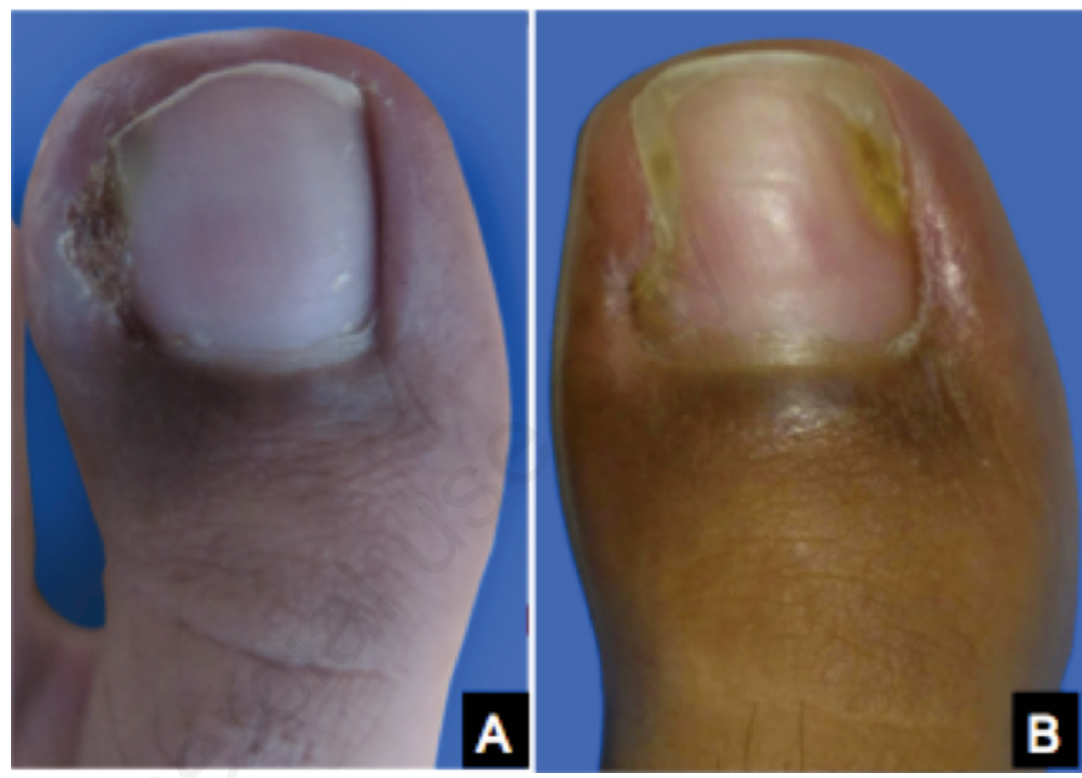

Figure 1. Ingrowing toenail on the left thumb. A) Before surgery; B) Two months after surgery.
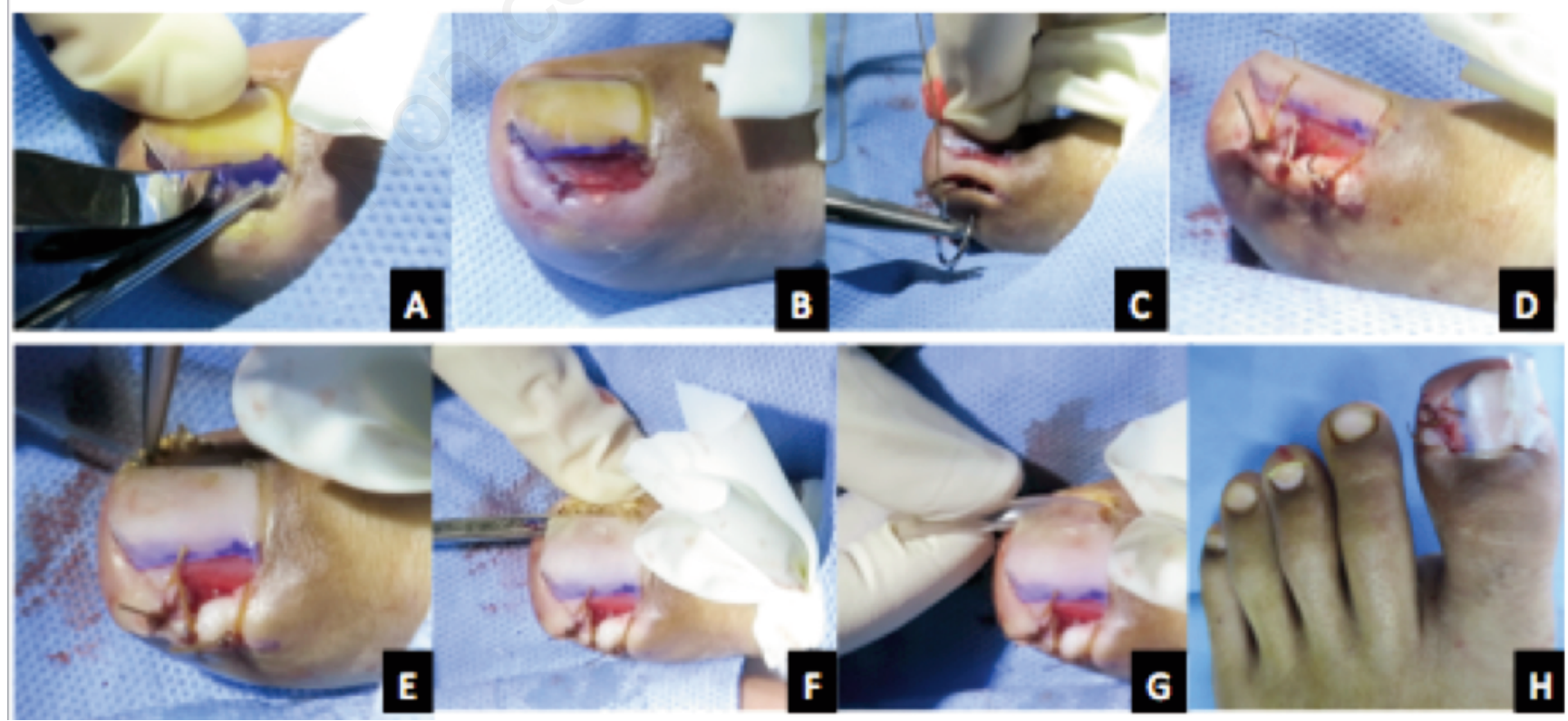

After

Figure 2. Decompression and gutter splint technique. (A-B) Partial avulsion of $20-25 \%$ of the lateral nail plate; (C-D) Excision of the soft tissue on the side of toe with onychocryptosis; (E-H) Insertion of infusion tube in the medial nail plate. 
vention. The conservative therapy for IT are gutter splint or sleeve technique, cottonwick insertion in the lateral groove corner, band-aid method, dental floss technique, nail wiring, angle correction technique, and acrylic artificial nail. There are also various surgical treatment options for IT. The ideal surgical procedure should result in a high level of patient satisfaction, both functional and aesthetic, rapid return to normal activities, and low rate of reccurence. ${ }^{1}$ The surgical procedure are Suppan I technique, Winograd procedure, decompression, Vandenbos, partial nail avulsion, partial chemical matricectomy, total matricectomy, and silicone gel sheets. ${ }^{1,9}$ Alternative procedures of IT include partial matricectomy via electrocautery, radiofrequency, and carbon dioxide laser ablation. Advantages of these techniques include less bleeding and reduced postoperative pain. ${ }^{9}$ The aim of decompression technique is to eliminate the mechanical compression pressure which responsible for the occurrence of IT. This procedure technique consist of removing the ingrowing part, which is almost onethird of the total nail plate. ${ }^{1}$ To prevent recurrence of IT, we expanded the nail bed by an elliptical incision of the soft tissue adjacent to the ingrowing side. This technique allowed the $180^{\circ}$ angle of the ingrowing nail bed to be increased to $190^{\circ}-200^{\circ}$ on the vertical plane. ${ }^{10}$ Aksakal et al. ${ }^{10}$ reported twenty-two patients with 30 cases of IT were treated by unilateral soft tissue resection combined with partail nail plate avulsion. Complete recovery was attained in $83,3 \%$ of cases and no complication was observed. Gutter treatment is a technique by insertion of a small guard between the later- al nail margin and the nail fold. A sterile plastic tube, most commonly intravenous drip infusion, is cut lenghtwise to open. ${ }^{4}$ Under local anaesthesia, the nail corner is elevated and the lateral nail margin freed, then allow the gutter to be slid over it. The gutter is fixed with one or two stitches, tape, or acyrlic glue. This place for a period of 6 to 8 weeks or even longer, during which the inflammatory changes will have subsided. The gutter not only protects the lateral nail groove, but also exerts some pressure on it making the granulation tissue disappear faster. ${ }^{11}$ We did the gutter splint technique as conservative therapy on the medial side of the toe. This technique provided good result and no staging progression of IT. The most common complications following nail surgery are regrowth of a nail spicule along the new lateral nail fold. ${ }^{9}$ Other complications are distal toe ischemia caused by prolonged application of the torniquet, damage the underlying tissues because overaggressive electrocautery to the nail matrix, infection, and lacerated nail bed when the nail is cut with the bandage scissors. ${ }^{12}$ There was no complication of surgery found in our patient.

\section{Conclusions}

Our cases highlight the need of identification and evaluation of IT staging to choose the correct management. This report confirms that combination therapy of decompression and gutter splint are low cost, easy to perform, and produces good cosmetic results with no reccurrence.

\section{References}

1. Khunger N, Kandhari R. Ingrown toenails. Indian $\mathrm{J}$ Dermatol Venereol Leprol. 2012;78:279-89.

2. Weaver TD, Ton MV, Pham TV. Ingrowing toenails: management practices and research outcomes. Int J Low Extrem Wounds. 2004;3(1):22-34.

3. DeLauro NM, DeLauro TM. Onychocryptosis. Clin Podiatr Med Surg. 2004;21:617-30.

4. Ezekian B, Englum BR, Gilmore BF, Kim J, Leraas HJ, Rice HE. Onychocrptosis in the pediatric patient: review and management techniques. Clin Pediatr. 2017;56(2):109-14.

5. Kline A. Onychocryptosis: a simple classification system. J Foot Ankle Surg. 2008;1(5):6.

6. Heifetz CJ. Ingrown toenail. A clinical study. Arm J Surg. 1937;38:298.

7. Martinez-Nova A, Sanchez-Rodriguez, Alonso-Pena. A new onychocryptosis classification and treatment plan. J Am Podiatr Med Assoc. 2007;97(5):389-93.

8. Park DH, Singh D. The management of ingrowing toenails. BMJ. 2012;344:1-6.

9. Heidelbaugh JJ, Lee H. Management of the ingrown toenail. Am Fam Physician. 2009;79(4):303-8.

10. Aksakal AB, Oztas P, Atahan C, Gurer MA. Decompression for the management of onychocryptosis. J Dermatol Treat. 2004;15:108-11.

11. Haneke E. Controversies in the treatment of ingrown toenails. Dermatol Res Pract. 2012:1-12.

12. Zuber TJ. Ingrown toenail removal. Am Fam Physician. 2002;65:2547-50. 